\title{
Trânsito gastrintestinal e digestibilidade aparente de nutrientes em eqüinos alimentados com dietas contendo grãos secos ou silagem de grãos úmidos de triticale ${ }^{1}$
}

\author{
Kátia de Oliveira ${ }^{2}$, Ciniro Costa ${ }^{3}$, Marília Gabriela Faustino ${ }^{4}$, Vanessa da Silva Gasque ${ }^{4}$, \\ Vanessa Pillon dos Santos ${ }^{4}$, Marina Noronha Lima ${ }^{4}$, Virgilio Franco do Nascimento Filho ${ }^{5}$, \\ Adibe Luiz Abdalla ${ }^{6}$
}

\footnotetext{
1 Parte do trabalho de tese de Doutorado da primeira autora, financiado com recursos da FAPESP.

2 Pós-Doutoranda - Departamento de Melhoramento e Nutrição Animal - FMVZ/UNESP, Campus de Botucatu, CEP: 18603-970 - SP

${ }^{3}$ Departamento de Melhoramento e Nutrição Animal - FMVZ/UNESP, Campus de Botucatu, CEP: 18603-970, Botucatu - SP.

${ }^{4}$ Faculdade de Ciências Agrárias da Universidade de Marília.

5 LIN/CENA - USP, CEP: 13400-970, Piracicaba - SP.

${ }^{6}$ LANA/CENA - USP, CEP: 13400-970, Piracicaba - SP.
}

RESUMO - Cinco éguas mestiças (idade e peso corporal médios de seis anos e 480 kg PV) foram distribuídas em delineamento experimental em quadrado latino para se e avaliar a utilização de dietas contendo grãos de triticale (secos ou ensilados) em substituição ao milho na alimentação de eqüinos, por meio do ensaio de avaliação do trânsito gastrintestinal e da digestibilidade. Os tratamentos consistiram de três níveis de grãos de triticale em substituição aos grãos de milho (0, 50 e $100 \%)$ e duas formas de conservação dos grãos de triticale (secos ou ensilados). As dietas foram isoprotéicas (12,5\% PB), com ingestão diária de MS pelos animais de 2,0\% PV (relação volumoso : concentrado de 50:50). Os coeficientes de digestibilidade aparente (CDa) da MS MO, PB e FDN foram determinados indiretamente. Os parâmetros de trânsito gastrintestinal avaliados foram: k1 (taxa de passagem pelo intestino grosso), k2 (taxa de passagem pelo estômago), TT (tempo de trânsito), TMR (tempo médio de retenção) e TMRT (tempo médio de retenção total). Não houve diferença para os CDa da MS, MO, PB e FDN entre as dietas experimentais, observando-se valores médios de 64,31; 65,14; 74,13 e 57,25\%, respectivamente. Considerando-se a cinética das fases sólida e líquida, notou-se efeito somente para k2 na fase sólida da digesta, cujo valor nas rações contendo $100 \%$ de triticale (seco ou ensilado) foi de $19,63 \% / \mathrm{h}$ e na dieta controle ( $0 \%$ de triticale), de $23,72 \% / \mathrm{h}$. Observou-se efeito linear crescente para o TT na fase sólida da digesta, com a elevação dos níveis de substituição dos grãos de milho pelos grãos de triticale ensilados. Concluiu-se que os concentrados para eqüinos podem ser formulados com grãos de triticale secos ou ensilados em substituição total ao milho. A inclusão de grãos de triticale na alimentação desta espécie animal promoveu trânsito lento da fase sólida da digesta.

Palavras-chave: cavalo, marcador, silagem, taxa de passagem

\section{Gastrointestinal transit and apparent digestibility of nutrients in equines fed with diets containing dry or high-moisture triticale grain silage}

\footnotetext{
ABSTRACT - Five crossbred mares (averaging six years and $480 \mathrm{~kg} \mathrm{BW}$ ) were allotted to latin square experimental design. The objective was to evaluate the utilization of diets containing triticale grains (dry or ensiled) in substitution of corn in the feeding of equine feeding, using assay of gastrointestinal transit and digestibility. The treatments consisted of three levels of triticale grains in substitution of corn grains (0,50 and 100\%), and two conservation forms of triticale grains (dry or ensiled) The diets were isoproteic (12.5\% CP), with aDM intake by the animals of 2,0\% BW (forage to concentrate 50:50). The apparent coefficients of digestibility ( $\mathrm{aCD}$ ) of the DM, OM, CP and NDF were determined by indirect method. The parameters of the gastrointestinal transit were: k1 (passage rate in the large intestine); k2 (passage rate in the stomach); TT (transit time) TMR (mean time retention) and TMRT (mean total retention time). No difference was observed for aCD of DM, OM, CP and NDF among the experimental diets, with means values of $64.31,65.14,74.13$ and 57.25\%, respectively. Considering the kinetics of the solid and liquid phases, it was found effect only to the $\mathrm{k} 2$ for the solid phase of digesta, whose values in the diets containing $100 \%$ triticale (dry or ensiled) was of $19.63 \% / \mathrm{h}$ and the control diet of $23.72 \% / \mathrm{h}$. An increasing linear effect was observed for TT in the solid phase of digesta, as the levels of substitution of corn grain by ensiled triticale grain increased. In conclusion, the concentrates for equines may be formulated with dry or ensiled triticale grains in total substitution of corn grains. The inclusion of the triticale grains in the equine feeding promoted slow transit of the digesta.
}

Key Words: horse, marker, passage rate, silage 


\section{Introdução}

A avaliação nutricional dos alimentos que compõem uma dieta é de grande importância, pois expressa o teor do nutriente aproveitado pelo animal. A cinética digestiva estuda o movimento de partículas pelo sistema digestivo, promovendo ligação entre a fisiologia clássica (motilidade intestinal) e a nutrição prática, auxiliando na formulação de estratégias digestivas para cada animal (Warner, 1981).

Reduzido número de trabalhos avaliando o trânsito gastrintestinal de eqüinos é encontrado nas literaturas nacional e internacional. As primeiras publicações sobre este assunto objetivaram a mensuração do tempo de passagem de partículas marcadas pelo trato digestivo de cavalos, cujos resultados foram divergentes. Hintz \& Loy (1966) relataram que o tempo de passagem do óxido crômico foi de 63 horas pós-alimentação, enquanto Haenlein et al. (1966) e Vander Noot et al. (1967) verificaram tempos de 48 e 96 horas, respectivamente. Recentemente, Oliveira et al. (2001), avaliando a cinética de passagem da digesta em eqüinos alimentados com dietas compostas de feno de coastcross e concentrado nas proporções de 100:0, 80:20, 60:40 e 40:60, observaram que o tempo de retenção da digesta variou de 40,58 a 47,95 horas, independentemente da dieta.

Considerando a capacidade digestiva dos nutrientes, Araújo (1999) realizou uma pesquisa comparando os principais métodos indiretos, em relação ao método de coleta total, para estimar a digestibilidade aparente dos nutrientes em eqüinos. Os resultados obtidos por esse autor demonstraram que os indicadores internos, cinzas insolúveis em ácido e em detergente ácido, foram eficientes para determinar este parâmetro. Similarmente, Cuddeford \& Hughes (1990) recomendam o uso da cinza insolúvel em ácido (CIA) como indicador de referência para quantificar a digestibilidade aparente de nutrientes para esta espécie animal, quando a coleta total de fezes for impraticável.

Na procura por alimentos alternativos aos grãos de milho, com a finalidade de reduzir os custos relacionados à alimentação, tem-se o triticale, um híbrido do trigo Triticum aestivum e do centeio Secale cereale (Lewis, 2000). Este grão merece destaque, pois é uma cultura com habilidade para adaptar-se às condições desfavoráveis, além de ser colhido no inverno, quando há maior escassez de milho, sendo sua composição química semelhante à do milho. Ainda, a maioria dos pesquisadores concorda que o triticale pode substituir integralmente os grãos de milho, sem interferir negativamente nos coeficientes de digestibilidade dos nutrientes para bovinos (Medroni et al., 2000; Prado et al., 2000).
São reduzidos os dados sobre o uso de grãos ensilados para cavalos, contudo, Santos et al. (2002), avaliando o fornecimento de grãos de milho ensilados, não observaram efeitos negativos deste alimento sobre a ingestão e aceitabilidade em eqüinos. Informações sobre o valor nutritivo de grãos de triticale (secos ou ensilados) para esta espécie inexistem na literatura consultada.

Objetivou-se com este trabalho avaliar a utilização de dietas contendo grãos de triticale, secos ou ensilados, em substituição ao milho, na alimentação de eqüinos, por meio da avaliação do trânsito gastrintestinal e da digestibilidade dos nutrientes das dietas.

\section{Material e Métodos}

O experimento foi conduzido no Setor de Eqüinocultura pertencente à Universidade de Marília, Marília - SP. Cinco éguas mestiças (idade e peso corporal [PC] médios de 6 anos e $480 \mathrm{~kg}$ ) foram distribuídas em delineamento experimental quadrado latino (5 x 5), designado por Cochran \& Cox (1967). Os tratamentos consistiram de dietas contendo três níveis (0, 50 e 100\%) de grãos de triticale em substituição aos de milho e dois processos de conservação dos grãos de triticale (secos e ensilados). As dietas, cujas composições química, centesimal e química encontram-se nas Tabelas 1, 2 e 3, respectivamente, foram formuladas para serem isoprotéicas, constituindo os seguintes tratamentos: controle: ração sem triticale seco (TS) ou ensilado (TE) + $100 \%$ de milho, ração com 50\% de triticale seco $+50 \%$ de milho, ração com $50 \%$ de triticale ensilado $+50 \%$ de milho, ração com $100 \%$ de triticale seco + $0 \%$ de milho e ração com $100 \%$ de triticale ensilado $+0 \%$ de milho.

Os grãos ensilados de triticale foram colhidos com $27 \%$ de umidade (U) e, em seguida, moídos em peneira com crivo de $6 \mathrm{~mm}$ e compactados em tambores experimentais de $100 \mathrm{~L}$. Os silos permaneceram fechados por um ano e, após abertura das silagens, foram coletadas amostras do material ensilado, que permaneceram em freezer a $-10^{\circ} \mathrm{C}$, para posteriores análises bromatológicas. A colheita dos grãos secos de triticale $(10,2 \% \mathrm{U})$ ocorreu 15 dias após a dos grãos ensilados. Em seguida, os grãos foram ensacados e expurgados insetos e, após secagem ao sol, coletadas amostras para posteriores análises.

A quantidade de alimento fornecida aos animais foi estabelecida segundo as recomendações do NRC (1989), para eqüinos, visando atender às exigências para esta categoria. Portanto, o consumo diário de MS foi equivalente a 2,0\% do PC das éguas alimentadas com dietas compostas por $50 \%$ de concentrado e $50 \%$ de feno de coastcross picado em triturador de faca. O concentrado 
e o feno foram fornecidos separadamente em três refeições (8h30, 13h30 e 16h30), sendo a última composta apenas por volumoso (Manzano \& Carvalho, 1978). As sobras foram retiradas e pesadas 15 minutos antes dos arraçoamentos, para se obter a quantidade de nutrientes ingeridos.

Tabela 1 - Teores dos nutrientes dos alimentos ${ }^{1}$ Table 1 - Nutrient contents of feeds

\begin{tabular}{|c|c|c|c|c|}
\hline \multirow[t]{2}{*}{$\begin{array}{l}\text { Alimento } \\
\text { Feed }\end{array}$} & \multirow[t]{2}{*}{$\begin{array}{c}\text { MS (\%) } \\
D M\end{array}$} & \multicolumn{3}{|c|}{$\begin{array}{c}\text { Nutriente (\% MS) } \\
\text { Nutrient (DM \%) }\end{array}$} \\
\hline & & $\begin{array}{l}\mathrm{PB} \\
C P\end{array}$ & $\begin{array}{l}\mathrm{EE} \\
E E\end{array}$ & FB \\
\hline $\begin{array}{l}\text { Milho em grão } \\
\text { Corn grain }\end{array}$ & 89,26 & 9,94 & 4,94 & 2,09 \\
\hline $\begin{array}{l}\text { Triticale (grão seco) } \\
\text { Triticale (dry grain) }\end{array}$ & 96,58 & 14,30 & 2,16 & 3,40 \\
\hline $\begin{array}{l}\text { Triticale (grão ensilado) } \\
\text { Triticale (ensiled grain) }\end{array}$ & 76,53 & 14,05 & 1,78 & 3,30 \\
\hline $\begin{array}{l}\text { Farelo de soja } \\
\text { Soybean meal }\end{array}$ & 89,20 & 49,33 & 2,42 & 6,47 \\
\hline $\begin{array}{l}\text { Farelo de trigo } \\
\text { Wheat bran }\end{array}$ & 89,70 & 17,05 & 2,59 & 10,57 \\
\hline $\begin{array}{l}\text { Feno de coastcross } \\
\text { Coastcross hay }\end{array}$ & 91,07 & 5,33 & $\mathrm{nd}^{2}$ & 40,50 \\
\hline
\end{tabular}

${ }^{1}$ Dados obtidos no laboratório de Nutrição Animal, do Centro de Energia Nuclear na Agricultura (CENA) USP; ${ }^{2}$ nd = não determinado.

${ }^{1}$ Calculed composition based on analyses in Animal Nutrition in Centro de Energia Nuclear na Agricultura (CENA) USP; ${ }^{2} n d=$ not determined.

Tabela 2 - Composições química dos alimentos e centesimal e química dos concentrados experimentais $(\% \mathrm{MS})^{1}$

Table 2 - Chemical feed composition and percentage and chemical compositions of the experimental concentrates (\%DM)

Alimento (\%) Nível de substituição do grão
Feed

Feed

de milho pelo grão de triticale (\%)

Level of substitution of corn grain by triticale grain

\begin{tabular}{ccc}
\hline 0 T & 50TS ou 50TE & 100TS ou 100TE \\
50DT or 50ET & 100DT or100ET \\
\hline
\end{tabular}

\begin{tabular}{lccc}
\hline $\begin{array}{l}\text { Milho, grão } \\
\begin{array}{l}\text { Corn grain } \\
\text { Triticale, grão }\end{array}\end{array}$ & 64 & 32 & - \\
$\begin{array}{l}\text { Triticale grain } \\
\text { Farelo de soja }\end{array}$ & 8 & 32 & 64 \\
$\begin{array}{l}\text { Soybean meal } \\
\text { Farelo de trigo }\end{array}$ & 15 & 6 & 4 \\
$\begin{array}{l}\text { Wheat bran } \\
\text { Feno de coastcross }\end{array}$ & 10 & 11 & 8 \\
$\begin{array}{l}\text { Coastcross hay } \\
\text { Sal + Mistura }\end{array}$ & 3 & 3 & 21 \\
Salt + Mixture & & & 3
\end{tabular}

Salt + Mixture

${ }^{1}$ OT = (1) $0 \%$ triticale seco(TS) ou ensilado (TE) (Controle); (2) 50TS ou (3) $50 \mathrm{TE}=50 \%$ triticale seco ou $50 \%$ triticale ensilado e (4) 100TS ou (5) $100 \mathrm{TE}$ $=100 \%$ triticale seco ou $100 \%$ triticale ensilado.

$10 T=(1) 0 \%$ dry (DT) or ensiled triticale (ET)(Control), (2) $50 D T$ or (3) $50 E T=50 \%$ dry triticale ou 50\% ensiled triticale and (4)100DT ou (5) 100ET $=100 \%$ dry triticale ou 100\% ensiled triticale.

${ }^{2}$ Composição da mistura mineral e vitamínica (Composition of mineral and vitamin mix): Ca, 185g; P, 180g; Mg, 25g; Zn, 5000 mg; Cu, 1300 mg; Cobalto, $350 \mathrm{mg} ; \mathrm{Mn}, 2.500 \mathrm{mg}$; Fe, $3.000 \mathrm{mg}$; I, 300 mg; Se, 20 mg; F, $1.800 \mathrm{mg}$; Vit. A, 5. $000 \mathrm{UI}$
Tabela 3 - Composição química dos cinco concentrados experimentais $^{1}$

Table 3 - Chemical composition of the five experimental concentrates

\begin{tabular}{|c|c|c|c|c|c|}
\hline \multirow[t]{2}{*}{$\begin{array}{l}\text { Nutriente }{ }^{2} \\
\text { Nutrient }\end{array}$} & \multicolumn{5}{|c|}{$\begin{array}{c}\text { Nível de substituição do grão } \\
\text { de milho pelo grão de triticale (\%) } \\
\text { Level of substitution of corn grain by triticale grain }\end{array}$} \\
\hline & $0 \mathrm{~T}$ & $\begin{array}{l}50 \mathrm{TS} \\
50 D T\end{array}$ & $\begin{array}{c}50 \mathrm{TE} \\
50 E T\end{array}$ & $\begin{array}{c}100 \mathrm{TS} \\
100 \mathrm{DT}\end{array}$ & $\begin{array}{c}100 \mathrm{TE} \\
100 \mathrm{ET}\end{array}$ \\
\hline MS (\%) (DM) & 90,54 & 90,57 & 81,36 & 90,48 & 75,11 \\
\hline PB $(\%)^{3}(C P)$ & 12,56 & 12,59 & 12,44 & 12,49 & 12,46 \\
\hline FDN (NDF) $(\%)^{3,4}$ & 40,50 & 43,64 & 42,04 & 45,98 & 46,50 \\
\hline $\mathrm{ED}(D E)(\mathrm{Mcal} / \mathrm{kg})^{5}$ & 3,30 & 3,18 & $\mathrm{NC}^{6}$ & 3,05 & NC \\
\hline
\end{tabular}

${ }^{1}$ OT = (1) $0 \%$ triticale seco(TS) ou ensilado (TE) (controle); (2) 50TS ou (3) $50 \mathrm{TE}=50 \%$ triticale seco ou $50 \%$ triticale ensilado e (4) 100TS ou (5) 100TE $=100 \%$ triticale seco ou $100 \%$ triticale ensilado.

2 Dados obtidos no laboratório de Nutrição Animal, do Centro de Energia Nuclear na Agricultura (CENA) USP: ${ }^{3}$ Nutrientes na matéria seca: ${ }^{4}$ FDN - fibra em detergente neutro; ${ }^{5}$ Energia digestível calculada, segundo Lewis (2000); ${ }^{6}$ NC - não calculado, por não haver dados disponíveis de ED para o grão de triticale úmido ensilado

1 OT = (1) O\% dry (DT) or ensiled triticale (ET)(Control), (2) $50 D T$ or (3) $50 E T=50 \%$ dry triticale ou $50 \%$ ensiled triticale and (4)100DT ou (5) 100ET $=100 \%$ dry triticale ou 100\% ensiled triticale.

2 Calculated composition based on analyses in Animal Nutrition in Centro de Energia Nuclear na Agricultura (CENA) USP; ${ }^{3}$ Nutrient in DM; ${ }^{4}$ NDF - neutral detergent neutral: ${ }^{5}$ Calculeted digestible energy, as Lewis (2000); ${ }^{N} \mathrm{NC}$ - non calculated, for not disponible data of digestible energy to high-moisture ensilated triticale grain.

O experimento teve duração total de 60 dias, subdivididos em cinco períodos de 12 dias cada um. Os primeiros seis dias corresponderam à fase de adaptação dos animais às instalações, dietas e condições de manejo, de acordo com as metodologias descritas por Gibbs et al. (1996) e Oliveira et al. (2003a), para os ensaios de digestibilidade, e Holland et al. (1998), para avaliação da cinética digestiva. A fase seguinte foi destinada à coleta parcial de fezes, com duração de seis dias, determinando-se, assim, os coeficientes de digestibilidade e as estimativas do trânsito gastrintestinal das dietas experimentais. Durante todo período experimental, os animais ficaram alojados em baia de alvenaria ( 4 x $4 \mathrm{~m}$ ), com piso de terra batida, comedouros para concentrado e feno e bebedouro para consumo de água ad libitum. Antes do início do experimento, foi administrado vermífugo de amplo espectro às éguas, que foram soltas em redondel no final de cada período.

Os coeficientes de digestibilidade aparente da MS, MO, PB e FDN foram determinados por método indireto, utilizando-se, como indicador interno, a cinza insolúvel em ácido clorídrico a 2N (CIA) (Van Keulen \& Young, 1977). As fezes foram coletadas diretamente do reto do animal, duas vezes ao dia, inicialmente às 8 e 14h, no segundo dia, às 9 e 15h e, assim, sucessivamente, até o último dia, com coletas às 13 e 19h, com a finalidade de se diminuir o efeito de variação diurna (Haenlein et al., 1966). Para estimativa da produção fecal, foram realizadas análises de CIA no 
concentrado e volumoso e nas fezes. Assim, a quantidade de MS fecal estimada foi obtida dividindo-se a quantidade consumida de CIA (g) pela porcentagem de CIA nas fezes e multiplicando-se o resultado por 100 (Araújo, 1999). As análises bromatológicas dos alimentos e das fezes foram feitas segundo a metodologia descrita por Silva (1989). Os cálculos dos CDa da MS e dos nutrientes avaliados foram obtidos por meio das seguintes fórmulas:

$$
\text { CDaMS }=100-100 \times \frac{\text { \% CIA na dieta }}{\text { \% CIA nas fezes }}
$$

\begin{tabular}{|c|c|c|c|}
\hline \multirow[t]{2}{*}{$\mathrm{CDaN}=100-100 \mathrm{x}$} & $\begin{array}{c}\% \text { CIA na MS } \\
\text { da dieta }\end{array}$ & $\mathrm{X}$ & $\begin{array}{c}\% \text { nutriente } \\
\text { nas fezes }\end{array}$ \\
\hline & $\begin{array}{c}\text { \% CIA na MS } \\
\text { das fezes }\end{array}$ & & $\begin{array}{c}\% \text { nutriente } \\
\text { na dieta }\end{array}$ \\
\hline
\end{tabular}

O monitoramento do trânsito gastrintestinal foi realizado com base no modelo proposto por Grovum \& Williams (1973), adaptando-o para o estudo com eqüinos, em que se avaliaram os seguintes parâmetros: $k 1$ - taxa de passagem da fração lenta da digesta, correspondendo ao intestino grosso; $k 2$ - taxa de passagem da fração rápida da digesta, referente ao estômago; TT - tempo de trânsito pelo compartimento tubular, intestino delgado; TMR - tempos médios de retenção do marcador pelos compartimentos com capacidade de mistura, estômago $\left(\mathrm{TMR}_{2}\right)$ e intestino grosso $\left(\mathrm{TMR}_{1}\right)$; e TMRT - tempo médio de retenção total do marcador, incluindo todo o trato digestivo. Foram usados como marcadores o Co-EDTA, para marcar a fase líquida, e o cromo mordentado à fibra do feno de coastcross (Cr-FDN), para marcar a fase sólida da digesta, segundo procedimento desenvolvido por Uden et al. (1980).

Os marcadores foram administrados no primeiro dia do período de coleta de fezes, quando foram fornecidos, em dose única, 3 g de Co-EDTA e $30 \mathrm{~g}$ de Cr-FDN (partículas de $1 \mathrm{~mm}$ ), juntamente com o concentrado no período da manhã. Neste procedimento, as sobras de alimento foram coletadas no último dia de adaptação (18 h), procedendo-se, no dia seguinte, à administração do Co-EDTA e Cr-FDNm, juntamente com palatabilizante (açúcar), oferecidos em um balde, para evitar a perda do marcador durante o consumo pelas éguas. As coletas de fezes (aproximadamente $200 \mathrm{~g} /$ animal) para determinação do marcador através do trato gastrintestinal foram realizadas nos tempos de 0,1 , 2, 4, 6, 8, 10,12, 16, 20, 24, 30, 36, 42, 48, 54, 60, 66, 72 e 78 horas pósdosagem, segundo a metodologia descrita por Cuddeford et al. (1992), que foi modificada por meio do acréscimo de quatro tempos de amostragem no período inicial das coletas (1, 2, 6 e 10 horas). Este procedimento foi necessário para aumentar a acurácia dos dados coletados, principalmente com relação à construção da curva de excreção do Co-EDTA . Como este marcador possui afinidade com a fase líquida da digesta e o eqüino possui estômago pequeno, é de se esperar que o trânsito das partículas neste local seja mais rápido do que normalmente ocorre nos ruminantes. Desta forma, para garantir uma curva de excreção do Co-EDTA característica, com distribuição exponencial, e considerando que não há na literatura dados suficientes sobre o tema, entendeu-se ser necessário adaptar o procedimento para cavalos. Os parâmetros de trânsito gastrintestinal, segundo Grovum \& Williams (1973), foram calculados por intermédio das seguintes equações:

$$
\mathrm{TT}=\frac{\ln \mathrm{A}_{2}-\ln \mathrm{A}_{1} ;}{k_{2}-k_{1}} \quad \mathrm{TMR}_{1}=\frac{1 ;}{k_{1}} \quad \mathrm{TMR}_{2}=1 ;
$$

$\mathrm{TMR}=\mathrm{TMR}_{1}+\mathrm{TMR}_{2}$ e $\mathrm{TMRT}=\mathrm{TT}+\mathrm{TMR}_{1}+\mathrm{TMR}_{2}$.

em que $\ln \mathrm{A}_{1}$ e $\ln \mathrm{A}_{2}$ são constantes do modelo sem valor biológico definido, obtidas por meio das equações de suas curvas lineares, ramos descendente e ascendente, respectivamente.

A recuperação dos marcadores foi determinada multiplicando-se a concentração do marcador nas fezes pela produção de fezes, estimada por meio da CIA, e dividindo-se este resultado pela quantidade de marcador ingerido (Krysl et al., 1988). O tempo para excretar $50 \%$ de cada marcador $\left(t_{50}\right)$ foi estimado diretamente do gráfico de recuperação acumulativa, por meio das equações de suas curvas. A análise dos marcadores ( $\mathrm{Cr}$ e Co), nas fezes e no material original, foi realizada por meio da técnica analítica nuclear de fluorescência de raio X por dispersão de energia (EDXRF), em equipamento disponível no Laboratório de Instrumentação Nuclear, da Divisão de Desenvolvimento de Métodos e Técnicas Analíticas e Nucleares do CENA/ USP (Nascimento Filho, 1999).

Os dados referentes aos coeficientes da digestibilidade e do trânsito gastrintestinal foram analisados por meio da análise de variância do Statistical Analysis System (SAS, 2000), em que as fontes de variação incluídas no modelo foram tratamento, período e animal. Procedeu-se ao desdobramento dos graus de liberdade de tratamentos em polinômios ortogonais e, para comparação entre médias, ao teste de Dunnett a 5\% de significância. 


\section{Resultados e Discussão}

Não houve diferença $(P>0,05)$ nos coeficientes de digestibilidade aparente da MS, MO, PB e FDN entre as dietas experimentais com níveis de triticale (seco ou ensilado) em substituição ao milho (Tabela 4).

Resultados concordantes foram publicados para diversas espécies de produção animal, em que a substituição total dos grãos de milho pelos de triticale não interferiu negativamente na digestibilidade dos principais nutrientes (Furlan et al., 1999; Medroni et al., 2000; Prado et al., 2000; Lima et al., 2001).

Não foi encontrada na literatura consultada a avaliação dos grãos ensilados de triticale na alimentação animal, da mesma forma como não há dados disponíveis sobre o fornecimento dos grãos de triticale (secos ou ensilados) na alimentação de eqüinos. Contudo, neste estudo, os valores médios dos CDa dos nutrientes para a dieta com grãos de milho corroboram os resultados obtidos por outros pesquisadores, utilizando-se o mesmo grão na dieta de cavalos, com valores de 64,07 a 68,91\%; 62,8 a 77,0\%; 50,94 a 58,84\% e 68,4\%, para o CDMS, CDPB, CDFDN e CDMO, respectivamente (Whitaker \& Carvalho, 1997; Gobesso, 2001; Oliveira \& Furtado, 2001; Santos et al., 2002). Portanto, pode-se considerar que os resultados dos CDa dos nutrientes nas dietas com a substituição do milho pelo triticale (seco ou ensilado) foram satisfatórios e, conseqüentemente, promissores na nutrição de cavalos como alimento alternativo.

A taxa média de recuperação do Co obtida neste estudo (60,03\%), nas fezes dos eqüinos, foi considerada baixa, de modo que a quantidade ( $3 \mathrm{~g} /$ cabeça) fornecida às éguas foi insuficiente para boa mensuração do elemento químico, por intermédio da técnica analítica nuclear de fluorescência de raios $\mathrm{X}$ por dispersão de energia (ED-XRF). Em contrapartida, a taxa de recuperação do $\mathrm{Cr}$ nas fezes eqüinas foi elevada (média de 94,20\%), utili- zando-se a mesma técnica analítica na quantificação do marcador (Tabela 5). Esta constatação está consoante com os resultados obtidos por Olsson et al. (1949), citados por Haenlein et al. (1966), de 99\% de recuperação do óxido crômico nas fezes de cavalos, por um período de 60 horas, e por Parkins et al. (1982), de 94,8\% de recuperação para o mesmo marcador em eqüinos. Desta forma, pode-se considerar que o fornecimento de $30 \mathrm{~g}$ Cr-FDN/animal, em dose única, aliado à técnica nuclear ED-XRF, foi adequado para o estudo do trânsito gastrintestinal em cavalos.

Não se verificou diferença significativa $(\mathrm{P}>0,05)$ para o $t_{50}$ entre os tratamentos para ambos os marcadores (Cr-FDN e Co-EDTA), obtendo-se médias de 34,68 e 20,07h, respectivamente (Tabela 5). De modo similar, Vander Noot et al. (1967), Cuddeford et al. (1992) e Pagan et al. (1998) encontraram tempos de 35, 30 e 33h para recuperação de $50 \%$ do óxido crômico, Cr-FDN e itérbio, respectivamente, em cavalos alimentados com uma mistura de grãos e volumoso. Pearson \& Merrit (1991), por sua vez, avaliando o trânsito gastrintestinal em cavalos consumindo feno $(73 \%$ FDN) ou palhada $(88,6 \%$ FDN) à vontade, verificaram efeito significativo $(\mathrm{P}<0,01)$ das dietas para o $\mathrm{t}_{50}$ do Cr-FDN e do Co-EDTA, observando-se valores de 25,8 e 21,3h para cavalos recebendo feno e de 31,3 e $27 \mathrm{~h}$ para a palhada, respectivamente.

A análise conjunta das curvas de recuperação acumulativa dos marcadores (Figuras 1 e 2), com os respectivos $t_{50}$ (Tabela 5), indica que o monitoramento do trânsito gastrintestinal em éguas, até 78 horas pós-dosagem, foi adequado para que ocorresse a estabilização destas curvas, pois 50\% do Cr-FDN e Co-EDTA foram recuperados no terço inicial do período de amostragem. Portanto, este fato expressa a importância de maior número de coletas de fezes na fase inicial de amostragem, na experimentação com eqüinos, principalmente, quando se utilizarem marcadores com afinidade com a fase líquida da digesta.

Tabela 4 - Digestibilidade aparente da MS e dos nutrientes em eqüinos alimentados com dietas contendo níveis de substituição do grão de milho pelo grão de triticale

Table 4 - Apparent digestibility of DM and nutrients in equines fed diets containing levels of substitution of corn grain by triticale grain

\begin{tabular}{|c|c|c|c|c|c|c|c|}
\hline \multirow[t]{3}{*}{$\begin{array}{l}\text { Digestibilidade } \\
\text { Digestibility }\end{array}$} & \multicolumn{5}{|c|}{$\begin{array}{l}\text { Nível de substituição do grão de milho pelo grão de triticale (\%) } \\
\text { Level of substitution of corn grain by triticale grain }\end{array}$} & \multirow[t]{3}{*}{$\begin{array}{l}\text { Média } \\
\text { Mean }\end{array}$} & \multirow[t]{3}{*}{ CV (\%) } \\
\hline & \multirow{2}{*}{$\begin{array}{c}0 \\
\begin{array}{c}\text { Controle } \\
\text { Control }\end{array}\end{array}$} & \multicolumn{2}{|c|}{50} & \multicolumn{2}{|c|}{100} & & \\
\hline & & $\begin{array}{c}\text { Seco } \\
\text { Dry }\end{array}$ & $\begin{array}{l}\text { Ensilado } \\
\text { Ensiled }\end{array}$ & $\begin{array}{c}\text { Seco } \\
\text { Dry }\end{array}$ & $\begin{array}{c}\text { Ensilado } \\
\text { Ensiled }\end{array}$ & & \\
\hline MS (DM) & 67,40 & 69,67 & 61,09 & 60,09 & 63,28 & 64,31 & 12,36 \\
\hline MO (OM) & 68,51 & 70,58 & 62,09 & 60,88 & 63,62 & 65,14 & 12,02 \\
\hline $\mathrm{PB}(C P)$ & 75,43 & 76,78 & 70,33 & 71,62 & 77,71 & 74,37 & 11,61 \\
\hline FDN (NDF) & 58,74 & 62,01 & 55,80 & 53,33 & 56,35 & 57,25 & 17,92 \\
\hline
\end{tabular}

Médias não diferem $(P>0,05)$ pelo teste Dunnett.

Means do not differ $(P>0.05)$ by Dunnett test. 
Diferentemente do que ocorre na experimentação com eqüinos, em ruminantes existe uma literatura vasta sobre o estudo do trânsito gastrintestinal que fornece dados de comparação aos eqüinos, haja vista, segundo Uden et al. (1982), a similaridade destes parâmetros entre as espécies. Verificou-se efeito significativo somente para o fluxo de k2 entre as dietas experimentais para fase sólida da digesta, em que os valores médios obtidos para os outros parâmetros, k1, TT e TMRT foram de 7,57\%/h, 28,96h e 47,8h, respectivamente (Tabela 6 ).

O fluxo de partículas da fase sólida da digesta pelo intestino grosso de eqüinos é representado pela taxa k1, com valor médio de $7,57 \%$, consumindo $50 \%$ de concentrado e $50 \%$ de volumoso (Tabela 6), superior aos valores encontrados em ruminantes consumindo a mesma proporção de alimentos, de 3 a 5\%/h, referindo-se ao rúmen (Vega et al., 1998; Soares et al., 2003). Esta taxa apresenta-se dentro do esperado, se considerado o aspecto anatômico distinto entre os compartimentos envolvidos nas espécies eqüina e bovina. Portanto, a taxa de saída de partículas da fase sólida da digesta no intestino grosso de cavalos é mais rápida que em bovinos, visto que, no rúmen, a taxa de esvaziamento apresenta-se mais lenta.

A avaliação do TT da fase sólida da digesta obtido nesta pesquisa $(28,96 \mathrm{~h})$ retrata o tempo requerido para a partícula percorrer o intestino delgado, o qual se assemelha ao valor registrado por Oliveira et al. (2003b), de 25,5h, em eqüinos consumindo ração com $60 \%$ de volumoso e $40 \%$ de

Tabela 5 - Recuperação (\%) e tempo de recuperação $\left(t_{50}\right)$ dos marcadores em eqüinos alimentados com dietas contendo níveis de substituição do grão de milho pelo grão de triticale

Table 5 - Recovery (\%) and recovery time $\left(t_{50}\right)$ of markers in equines fed diets containing levels of substitution of corn grain by triticale grain

\begin{tabular}{|c|c|c|c|c|c|c|c|}
\hline \multirow[t]{2}{*}{ Item } & \multicolumn{5}{|c|}{$\begin{array}{l}\text { Nível de substituição do grão de milho pelo grão de triticale (\%) } \\
\text { Level of substitution of corn grain by triticale grain }\end{array}$} & \multirow[t]{2}{*}{$\begin{array}{l}\text { Média } \\
\text { Mean }\end{array}$} & \multirow[t]{2}{*}{ CV (\%) } \\
\hline & $\begin{array}{c}0 \\
\begin{array}{c}\text { Controle } \\
\text { Control }\end{array}\end{array}$ & \multicolumn{2}{|c|}{50} & \multicolumn{2}{|c|}{100} & & \\
\hline \multicolumn{8}{|l|}{ Cr-FDN } \\
\hline $\mathrm{t}_{50}(\mathrm{~h})$ & 32,54 & 36,15 & 34,84 & 36,22 & 33,64 & 34,68 & 20,04 \\
\hline \multicolumn{8}{|l|}{ Co-EDTA } \\
\hline $\begin{array}{l}\text { Recuperação (\%) } \\
\text { Recovery }\end{array}$ & 64,50 & 56,43 & 55,85 & 64,07 & 59,28 & 60,03 & 43,46 \\
\hline $\mathrm{t}_{50}(\mathrm{~h})$ & 19,96 & 19,96 & 20,31 & 20,08 & 20,05 & 20,07 & 34,48 \\
\hline
\end{tabular}

Médias não diferem $(P>0,05)$ pelo teste Dunnett.

Means do not differ $(P>0.05)$ by Dunnett test.

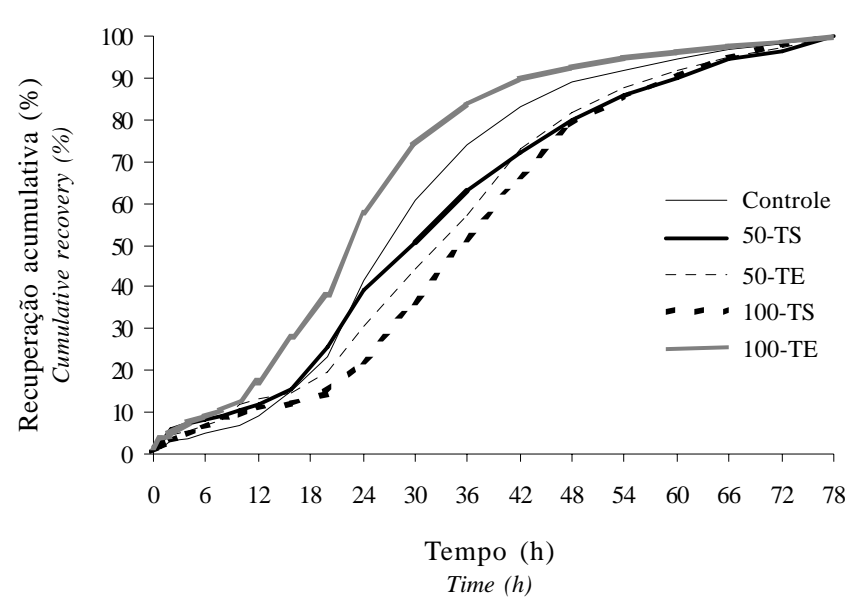

Figura 1 - Média acumulativa (\%) das taxas de recuperação do $\mathrm{Cr}$ para eqüinos alimentados com dietas contendo níveis crescentes de grãos de triticale.

Figure 1 - Cumulative mean (\%) of the recovery rates of $\mathrm{Cr}$ for equines fed diets containing increasing levels of triticale grains.

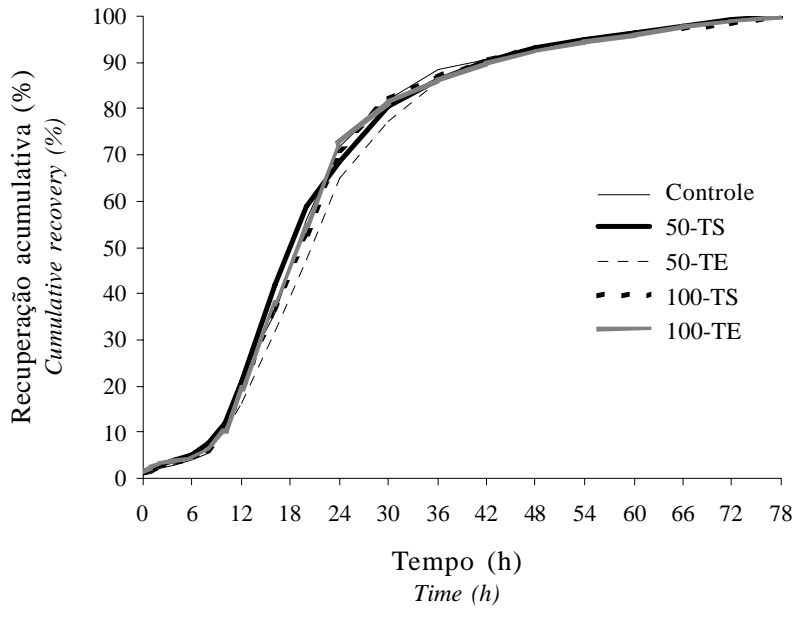

Figura 2 - Média acumulativa (\%) das taxas de recuperação do Co para eqüinos alimentados com dietas contendo níveis crescentes de grãos de triticale.

Figure 2 - Cumulative mean (\%) of the recovery rates of Co for equines fed diets containing increasing levels of triticale grains. 
Tabela 6 - Taxa de passagem no intestino grosso (k1), taxa de passagem no estômago (k2), tempo de trânsito (TT) e tempo médio de retenção total (TMRT) da fase sólida da digesta de eqüinos alimentados com dietas contendo níveis de substituição do grão de milho pelo grão de triticale

Table 6 - $\quad$ Passage rate in large intestine (k1), passage rate in stomach ( $k 2$ ), transit time (TT) and total mean retention time (TMRT) of the solid phases of digesta in equines fed diets containing levels of substitution of corn grain by triticale grain

\begin{tabular}{|c|c|c|c|c|c|c|c|}
\hline \multirow[t]{3}{*}{$\begin{array}{l}\text { Parâmetro } \\
\text { Parameter }\end{array}$} & \multicolumn{5}{|c|}{$\begin{array}{l}\text { Nível de substituição do grão de milho pelo grão de triticale (\%) } \\
\text { Level of substitution of corn grain by triticale grain }\end{array}$} & \multirow[t]{3}{*}{$\begin{array}{l}\text { Média } \\
\text { Mean }\end{array}$} & \multirow[t]{3}{*}{ CV (\%) } \\
\hline & \multirow{2}{*}{$\begin{array}{c}0 \\
\text { Controle } \\
\text { Control }\end{array}$} & \multicolumn{2}{|c|}{50} & \multicolumn{2}{|c|}{100} & & \\
\hline & & $\begin{array}{r}\text { Seco } \\
\text { Dry }\end{array}$ & $\begin{array}{l}\text { Ensilado } \\
\text { Ensiled }\end{array}$ & $\begin{array}{l}\text { Seco } \\
\text { Dry }\end{array}$ & $\begin{array}{l}\text { Ensilado } \\
\text { Ensiled }\end{array}$ & & \\
\hline k1 (\%/h) & $8,30 a$ & 7,59a & $7,60 \mathrm{a}$ & $7,14 a$ & $7,21 \mathrm{a}$ & 7,57 & 17,75 \\
\hline k2 (\%/h) & $23,72 b$ & 20,40 a & $20,87 a$ & $19,84 b$ & $19,41 \mathrm{~b}$ & - & 12,49 \\
\hline $\mathrm{TT}$ (h) & $17,36 \mathrm{a}$ & $27,97 a$ & $32,26 a$ & $32,64 a$ & $38,63 a$ & 28,96 & 41,82 \\
\hline TMRT (h) & $39,60 a$ & $46,19 a$ & $49,73 a$ & $51,32 a$ & $52,16 a$ & 47,80 & 25,43 \\
\hline
\end{tabular}

Médias com letras diferentes, na mesma linha, diferem $(\mathrm{P}<0,05)$ do controle pelo teste Dunnett.

Means with different letters within a row differ $(P<0.05)$ from the control by Dunnett test.

concentrado, e supera o TT de 18,1h para a mesma espécie animal alimentando-se com dieta mista (Holland et al., 1998). Este parâmetro foi superior ao obtido com ruminantes, cujas médias variaram de 12 a 23h para bovinos recebendo uma mistura de concentrado e volumoso (Krysl et al., 1998). Diferentemente, o TMRT (Tabela 6) apresentou média de 47,8h para a partícula percorrer todo o trato digestivo inteiro; em ruminantes alimentados com dietas contendo $50 \%$ de concentrado e $50 \%$ de volumoso, esta média variou de 58 a 64h (Ezequiel et a.l., 2003).

Nesta pesquisa, com relação à taxa de passagem de partículas pelo estômago dos eqüinos da fase sólida da digesta ( $k 2)$, constatou-se que a substituição total dos grãos de milho pelos de triticale (seco ou ensilado) diminuiu $(\mathrm{P}<0,05)$ a velocidade de esvaziamento do compartimento ( $\mathrm{k} 2$ médio de $19,63 \% / h)$, ao passo que a dieta controle ( $0 \%$ de triticale) apresentou a maior taxa de passagem das partículas de 23,72\%/h. De modo semelhante, Holmes et al. (1974) identificaram, em suínos alimentados com grãos ensilados de milho, menor taxa de esvaziamento do estômago em comparação aos grãos secos.

Em animais herbívoros, a lentidão do fluxo da digesta, devido à presença de pentosanas, não está totalmente comprovada, mas pesquisas conduzidas por Hill \& Utley (1988) e Goonewardene et al. (1994) parecem confirmar esta constatação, também ocorrida neste trabalho. Esses autores verificaram a necessidade de maior tempo em dias para a adaptação das novilhas alimentadas com dieta à base de triticale fato que pode estar associado ao trânsito da digesta mais lento pelo trato digestivo dos bovinos, posto que Warner (1981) considera o período de adaptação a uma nova dieta como utilização prática dos conhecimentos adquiridos com o estudo do trânsito gastrintestinal, que fornece condições para adequar os dias necessários para o período de adaptação (longos ou curtos). Ainda sobre esta questão, Lewis (2000) relatou que, na alimentação de eqüinos, o grão de trigo - um dos constituintes do triticale -, dependendo do seu grau de moagem (grosseiro ou fino), reveste-se de problemas relacionados à sua consistência, que se torna pegajosa, podendo acarretar distúrbios digestivos. Apesar disso, o pesquisador declarou que o grão de triticale pode ser um alimento nutritivo para esta espécie animal.

As pentosanas solúveis em água presentes no triticale, além de estarem relacionadas ao surgimento de viscosidade, também possuem a característica de reter grande volume de água no trato digestivo (Rundgreen, 1988). Corroborando os resultados obtidos por esses pesquisadores, nesta pesquisa, identificou-se, por meio da análise de regressão, efeito linear crescente $(P<0,05)$ para o teor de água retido nas fezes das éguas, com o aumento dos níveis de substituição dos grãos de milho pelos grãos secos de triticale (Figura 3).

Entretanto, tem sido verificada redução no teor de polissacarídeos não-amiláceos - PNA (pentosanas e $\beta$-glucanos), em grãos ensilados de cereais, observando-se reduzidos teores de $\beta$-glucanos nos grãos ensilados de aveia e cevada, devido à ação de enzimas produzidas pelos microrganismos e de ácidos orgânicos (Svihus et al., 1997). Portanto, espera-se que os concentrados formulados com grãos ensilados de triticale não apresentem alteração no teor de umidade nas fezes, como conseqüência da redução dos teores de PNA destes grãos armazenados anaerobiamente. Esta observação parece ser comprovada, indiretamante, pela maior retenção de água nas fezes observada somente nas éguas que consumiram as rações contendo grãos secos de triticale.

Adicionalmente, observou-se efeito linear crescente $(\mathrm{P}<0,05)$ para o TT de partículas da fase sólida da digesta, 


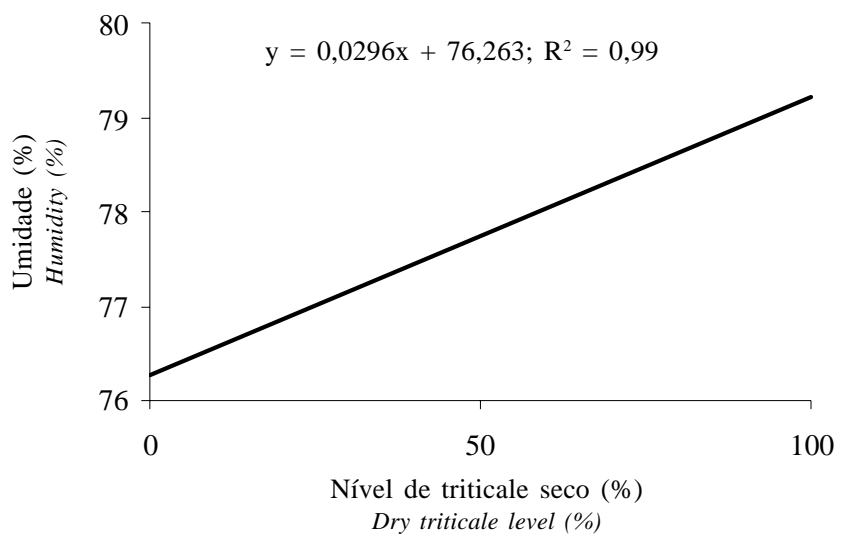

Figura 3 - Estimativa da retenção de água nas fezes eqüinas, em função dos níveis de grãos de triticale secos nos concentrados.

Figure 3 - Estimate of the water retention in equines faeces in relation to the levels of dry triticale grains in the concentrates.

com a elevação dos níveis de substituição dos grãos de milho pelos ensilados de triticale, o mesmo não ocorrendo para os grãos secos. A equação da reta foi: $\mathrm{Y}=0,2127 \mathrm{x}+$ $18,782\left(r^{2}=0,95\right)$, resultado que se deve, provavelmente, à presença de pentosanas solúveis em água no triticale, pois sabe-se que a presença destas substâncias na alimentação de monogástricos aumenta a viscosidade do conteúdo intestinal, reduzindo a taxa de passagem da digesta (Ferreira, 1994). Contudo, a análise dos resultados envolvendo as variáveis com capacidade de modificar o trânsito da digesta, apresentados neste trabalho, deve ser avaliada com cautela, pois há necessidade de mais pesquisas para esclarecer efeitos como teor de pentosanas, grãos ensilados e interação destes fatores na alimentação de eqüinos.

Considerando-se a fase líquida da digesta, não foi verificado efeito $(\mathrm{P}>0,05)$ para nenhum dos parâmetros de trânsito gastrintestinal avaliados em eqüinos alimentados com níveis de grãos de triticale (secos ou ensilados) em substituição aos de milho (Tabela 7). Estes resultados sugerem não haver interferência da presença de pentosanas, contidas nos grãos de triticale nesta fase da digesta, além de indicar que o efeito desta substância desapareceu, durante a fase sólida da digesta, no intestino grosso das éguas, graças, principalmente, à ação dos microrganismos presentes neste segmento, que possuem capacidade de digerir os polissacarídeos não-amiláceos na parede celular do triticale.

Os valores médios encontrados neste estudo para k1, k2, TT e TMRT, na fase líquida da digesta de eqüinos, foram de $6,55 \% / \mathrm{h}, 30,11 \% / \mathrm{h}, 5,06 \mathrm{~h}$ e $25,9 \mathrm{~h}$, respectivamente, sendo os valores para TT e TMRT inferiores aos resultados obtidos para os mesmos parâmetros verificados na fase sólida da digesta. Este comportamento ocorreu também nos ensaios desenvolvidos com ruminantes, demonstrando que o trânsito na fase líquida da digesta foi mais rápido que na fase sólida, como era esperado, independentemente da relação concentrado:volumoso (Vega e Poppi, 1997; Vega et al., 1998; Bueno, 2002). Contraditoriamente, as principais pesquisas com eqüinos que avaliaram o trânsito gastrintestinal das fases sólida e líquida da digesta, identificaram similaridade entre os fluxos das duas fases na digesta em cavalos alimentados com volumoso (Pearson \& Merrit, 1991; Wanderley et al., 1992; Cuddeford et al., 1995; Oliveira et al., 2003b).

Vale ressaltar que, nesta pesquisa, o trânsito lento de partículas na fase sólida da digesta obtida nas éguas recebendo dieta contendo grãos de triticale (seco e ensilado), em substituição ao milho, apesar de não ter melhorado a digestibilidade dos nutrientes, deve ser avaliado como

Tabela 7 - Taxa de passagem no intestino grosso (k1), taxa de passagem no estômago (k2), tempo de trânsito (TT) e tempo médio de retenção total (TMRT) da fase líquida da digesta de eqüinos alimentados com dietas contendo níveis de substituição do grão de milho pelo grão de triticale

Table 7 - $\quad$ Passage rate in large intestine ( $k 1)$, passage rate in the stomach ( $k 2)$, transit time (TT) and total mean retention time (TMRT) of the liquid phases of digesta in equines fed diets with levels of substitution of corn grain by triticale grain

\begin{tabular}{|c|c|c|c|c|c|c|c|}
\hline \multirow[t]{3}{*}{$\begin{array}{l}\text { Parâmetro } \\
\text { Parameter }\end{array}$} & \multicolumn{5}{|c|}{$\begin{array}{l}\text { Nível de substituição do grão de milho pelo grão de triticale (\%) } \\
\text { Level of substitution of corn grain by triticale grain }\end{array}$} & \multirow[t]{3}{*}{$\begin{array}{l}\text { Média } \\
\text { Mean }\end{array}$} & \multirow[t]{3}{*}{ CV (\%) } \\
\hline & \multirow{2}{*}{$\begin{array}{c}0 \\
\begin{array}{c}\text { Controle } \\
\text { Control }\end{array}\end{array}$} & \multicolumn{2}{|c|}{50} & \multicolumn{2}{|c|}{100} & & \\
\hline & & $\begin{array}{c}\text { Seco } \\
\text { Dry }\end{array}$ & $\begin{array}{c}\text { Ensilado } \\
\text { Ensiled }\end{array}$ & $\begin{array}{l}\text { Seco } \\
\text { Dry }\end{array}$ & $\begin{array}{l}\text { Ensilado } \\
\text { Ensiled }\end{array}$ & & \\
\hline k1 (\%/h) & 5,99 & 6,18 & 6,44 & 6,92 & 7,21 & 6,55 & 18,44 \\
\hline k2 (\%/h) & 28,27 & 31,79 & 31,47 & 33,99 & 25,02 & 30,11 & 31,14 \\
\hline $\mathrm{TT}$ (h) & 4,17 & 3,23 & 4,18 & 6,38 & 7,34 & 5,06 & 55,98 \\
\hline TMRT (h) & 24,96 & 22,61 & 24,65 & 24,66 & 32,63 & 25,90 & 25,99 \\
\hline
\end{tabular}

Médias não diferem $(P>0,05)$ pelo teste Dunnett

Means do not differ $(P>0.05)$ by Dunnett test. 
aspecto benéfico na nutrição de eqüinos. Este comportamento de trânsito observado pode diminuir a condução de grãos para o trato posterior, aumentando a absorção de amido no intestino delgado e, assim, reduzindo os distúrbios abdominais (Wolter, 1977). Deve-se salientar ainda que, durante o período experimental, não foi observado nenhum tipo de desconforto abdominal nas éguas que consumiram grãos secos ou ensilados de triticale.

\section{Conclusões}

Os concentrados para eqüinos podem ser formulados com grãos secos ou ensilados de triticale em substituição total ao milho, sem afetar adversamente a absorção dos nutrientes, tornando-se um alimento energético alternativo para esta espécie animal.

A inclusão de grãos de triticale (secos e ensilados) na alimentação de eqüinos promove trânsito lento da fase sólida da digesta pelo estômago e intestino delgado.

\section{Literatura Citada}

ARAÚJO, K.V. Métodos para determinação da digestibilidade aparente dos nutrientes em eqüinos. Lavras: Universidade Federal de Lavras, 1999. 155p. Tese (Doutorado em Zootecnia) - Universidade Federal de Lavras, 1999.

BUENO, I.C.S. Cinética digestiva e síntese microbiana ruminal em ovinos alimentados com fenos de três qualidades distintas. Piracicaba: Escola Superior de Agricultura Luiz de Queiroz, 2002. 89p. Tese (Doutorado em Ciência Animal) - Escola Superior de Agricultura Luiz de Queiro, 2002.

COCHRAN, W.G.; COX, G.M. Experimental designs. New York: John Wiley and Sons, 1967. 617p.

CUDDEFORD, D.; HUGHES, D. A comparison between chromiummordanted hay and acid-insoluble ash to determine apparent digestibility of a chaffed, molasses hay/straw mixture. Equine Veterinary Journal, v.22, n.2, p.122-125, 1990.

CUDDEFORD, D.; WOODHEAD, A.; MUIRHEAD, R.H. A comparison between the nutritive value of short-cutting cycle, high temperature-dried alfalfa and timothy hay for horses. Equine Veterinary Journal, v.24, p. 84-89, 1992.

CUDDEFORD, D.; PEARSON, R.A.; ARCHIBALD, R.F. et al. Digestibility and gastro-intestinal transit time of diets containing different proportions of alfalfa and oats straw given to Thoroughbreds, Shetland ponies, Highland ponies and donkeys. Animal Science, v.61, p.407-417, 1995.

EZEQUIEL, J.M.B.; QUEIROZ, M.A.A.; MENDES, A.R. et al. Taxa de passagem, consumo e digestibilidade da fibra da cana de açúcar”in natura” ou hidrolisada em bovinos. In: REUNIÃO ANUAL DA SOCIEDADE BRASILEIRA DE ZOOTECNIA, 40., 2003, Santa Maria. Anais... Santa Maria: Sociedade Brasileira de Zootecnia/Gmosis, 2003 (CD-ROM).

FERREIRA, W.M. Os componentes da parede celular vegetal na nutrição de não-ruminantes. In: REUNIÃO ANUAL DA SOCIEDADE BRASILEIRA DE ZOOTECNIA, 31., 1994, Maringá. Anais... Maringá: Sociedade Brasileira de Zootecnia/ Gmosis, 1994. p.511-513.

FURLAN, A.C.; MIKAMI, F.; MOREIRA, I. et al. Uso do triticale (Triticum turgidosecale) na alimentação de suínos em crescimento (25-60 kg). Revista Brasileira Zootecnia, v.28, n.5, p.1042-1049, 1999.
GIBBS, P.G.; POTTER, G.D.; SCHELLING, G.T. et al. The significance of small vs large intestinal digestion of cereal grain and oilseed protein in the equine. Journal Equine Veterinary Science, v.16, n.2, p.60-65, 1996.

GOBESSO, A.A.O. Digestão pré-cecal e total de nutrientes utilizando dietas para eqüinos fistulados no íleo. Jaboticabal: Universidade Estadual Paulista, 2001. 89p. Tese (Doutorado em Nutrição Animal) - Universidade Estadual Paulista, 2001

GONNEWARDENE, L.A.; ZOBELL, D.R.; BASARAB, J.A. Comparison of growth and feed efficiency of steers fed barley and triticale diets. Canadian Journal Animal Science, v.74, n.1, p.159-161, 1994.

GROVUM, W.L.; WILLIAMS, V.J. Rate of passage of digesta in sheep. 4. Passage of marker through the alimentary tract and the biological relevance of rate constants derived from the changes in concentration of marker in faeces. British Journal Nutrition, v.30, p.313-329, 1973.

HAENLEIN, G.F.; SMITH, R.C.; YOON, Y.M. Determination of the faecal excretion rate of horses with chromic oxide. Journal of Animal Science, v.25, n.4, p.1091-1095, 1966.

HILL, G.M.; UTLEY, P.R. Beagle 82 triticale and kline barley digestibility and utilization by cattle. Journal of Animal Science, v.66, p.474, 1988 (suppl. 1).

HOLLAND, J.L.; KRONFELD, D.S.; SKLAND, D. et al. Calculation of fecal kinetics in horses fed hay or hay and concentrate. Journal of Animal Science, v.76, p.1937-1944, 1998.

HOLMES, J.H.G.; BAYLEY, H.S.; HORNEY, F.D. Digestion of dry and high-moisture maize diets in the stomach of the pig. British Journal Nutrition, v.32, p.639-646, 1974.

KRYSL, L.J.; GALYEAN, M.L.; ESTELL, R.E. et al. Estimating digestibility and faecal output in lambs using internal and external markers. Journal of Agriculture Science, v.111, p. 19-25, 1988.

LEWIS, L.D. Nutrição clínica eqüina: alimentação e cuidados. São Paulo: Roca, 2000. 710p.

LIMA, G.J.M.M. Sorgo: alternativa de energia para rações. Alimentação Animal, n.3, p.8-9, 1998.

MANZANO, A.; CARVALHO, R.T.L. Digestibilidade aparente de uma ração peletizada e do arraçoamento tradicional em eqüinos. Pesquisa Agropecuária Brasileira, v.14, n.4, p.73-80, 1978.

MEDRONI, S.; PRADO, I.N.; NASCIMENTO, W.G. et al. Efeito da combinação de dietas contendo milho ou triticale e farelo de soja ou levedura sobre o desempenho de novilhas Nelore terminadas em confinamento. Acta Scientiarum, v.22, n.3, p.787-791, 2000.

NASCIMENTO FILHO, V.F. Técnicas analíticas nucleares de fluorescência de raios $X$ por dispersão de energia (EDXRF) e por reflexão total (TXRF). Piracicaba: Escola Superior de Agricultura Luiz de Queiroz, 1999. 32p.

NATIONAL RESEARCH COUNCIL - NRC. Requirements of domestic animals. Nutrient requirements of horse. 5.rev.ed. Washington: National Academy of Science, 1989. $100 \mathrm{p}$.

OLIVEIRA, K.; FURTADO, C.E. Digestibilidade aparente de dietas com diferentes níveis de farelo de canola para cavalos. Revista Brasileira de Zootecnia, v.30, n.1, p.181-186, 2001.

OLIVEIRA, C.A.A.; ALMEIDA, F.Q.; VALADARES FILHO, S.C. et al. Estimativa da digestibilidade aparente de nutrientes em dietas para eqüinos, com o uso de óxido crômico e indicadores internos. Revista Brasileira Zootecnia, v.32, n.6, p.16811689, 2003a (suppl. 1).

OLIVEIRA, C.A.A.; ALMEIDA, F.Q.; VIEIRA, A.A. et al. Cinética de passagem da digesta, balanço hídrico e de nitrogênio em eqüinos consumindo dietas com diferentes proporções de volumoso e concentrado. Revista Brasileira Zootecnia, v.32, n.1, p.140-149, 2003b.

PAGAN, J.D.; HARRIS, P.A.; BREWSTER-BARNES, T. et al. Exercise affects digestibility and rate of passage of all-forage 
and mixed diets in thoroughbreds horses. Journal Nutrition, v.128, p.2704S-2707S, 1998.

PARKINS, J.J.; SNOW, D.H.; ADAMS, S. The apparent digestibility of 'complete diet' cubes given to throughbred horses and the use of chromic oxide as an inert faecal marker. British Veterinary Journal, v.138, p.350-355, 1982.

PEARSON, R.A.; MERRIT, J.B. Intake, digestion and gastrointestinal transit time in resting donkeys and ponies and exercised donkeys given ad libitum hay and straw diets. Equine Veterinary Journal, v.23, n.5, p.339-343, 1991.

PRADO, I.N.; NASCIMENTO, W.G.; ZEOULA, L.M. et al. Níveis de triticale em substituição ao milho no desempenho zootécnico e digestibilidade aparente de novilhas Nelore confinadas. Revista Brasileira Zootecnia, v.29, n.5, p.1545-1552, 2000a.

RUNDGREN, M. Evaluation of triticale given to pigs, poultry and rats. Animal Feed Science and Technology, v.19, n.1-2, p.359-375, 1988.

SANTOS, C.P.; FURTADO, C.E.; JOBIM, C.C. et al. Avaliação da silagem de grãos úmidos de milho na alimentação de eqüinos em crescimento: valor nutricional e desempenho. Revista Brasileira Zootecnia, v.31, n.3, p.1214-1222, 2002.

STATISTICAL ANALYSIS SYSTEM - SAS. SAS user's: guide: statistics. Cary: 2000. 211p.

SILVA, D.J. Análise de alimentos (métodos químicos e biológicos). Viçosa, MG: Universidade Federal de Viçosa, 1989. 166p.

SOARES, J.P.G.; DERESZ, F.; AROEIRA, L.J.M. et al. Efeito da suplementação de concentrado sobre o consumo, conteúdo ruminal, taxa de passagem pelo trato gastrintestinal e parâmetros ruminais de vacas mestiças recebendo capim elefante picado. In: REUNIÃO ANUAL DA SOCIEDADE BRASILEIRA DE ZOOTECNIA, 40., 2003, Santa Maria. Anais... Santa Maria: Sociedade Brasileira de Zootecnia/Gmosis, 2003 (CD-ROM).

SVIHUS, B.; HERSTAD, O.; NEWMAN, C.V. Effect of high-moisture storage of barley, oats and wheat on chemical content and nutritional value for broiler chickens. Acta Agriculture Scandinavia, v.47, p.39-47, 1997.

UDEN, P.; COLUCCI, P.E.; van SOEST, P.J. Investigation of chromium, cerium and cobalt as markes in digesta. Rate of passage studies. Journal Science Food Agriculture, v.31, p.625-632, 1980.
UDEN, P.; ROUNSAVILLE, T.R.; WIGGANS, G.R. et al. The measurement of liquid and solid digesta retention in ruminants, equines and rabbits given Timothy hay. British Journal Nutrition, v.48, p.329-339, 1982.

VANDER NOOT, G.W.; SYMONS, L.D.; JYDMAN, R.K. Rate of passage of various feedstuffs through the digestive tract of horses. Journal of Animal Science, v.26, n.6, p.1309-1311, 1967.

Van KEULEN, J.; YOUNG, B.A. Evaluation of acid insoluble ash as a natural marker for digestibility studies. Journal of Animal Science, v.44, n.2, p.282-287, 1977.

VEGA, A.; POPPI, D.P. Extent of digestion and rumen condition as factor affecting passage of liquid and digesta particles in sheep. Journal of Agriculture Science, v.128, p.207-215, 1997.

VEGA, A.; GASA, J.; CASTRILLO, C. et al. Passage through the rumen and large intestine of sheep estimated from faecal marker excretion curves and slaughter trials. British Journal Nutrition, v.80, p.381-389, 1998.

WANDERLEY, R.C.; MANZANO, A.; ESTEVES, S.S. et al. Cinética da passagem da digesta em eqüinos. In. REUNIÃO ANUAL DA SOCIEDADE BRASILEIRA DE ZOOOTECNIA, 29., 1992, Lavras. Anais... Lavras: Sociedade Brasileira de Zoootecnia, 1992. p. 284

WARNER, A.C.I. Rate of passage of digesta through the gut of mammals and birds. Nutrition Abstracts Reviews, v.51, n.12, p.789-820, 1981.

WHITAKER, H.M.; CARVALHO, R.L. Substituição do milho pelo sorgo em rações para eqüinos. Revista Brasileira Zootecnia, v.26, n.1, p.139-143, 1997.

WOLTER, R. Alimentacion del caballo. Zaragoza: Acribia, 1977. $172 p$. 